\title{
Gelişmiş Ülkelerde Ve Avrupa Birliği'nde Borç Krizinin Etkileri Ve
}

\section{Çözüm Yolları}

Metin MERIÇ*

Emre ATSAN**

\section{Özet}

1929 Dünya Ekonomik Buhranından bu yana yaşanan ekonomik krizler gelişmiş ekonomilerde çok ciddi borç sorununa yol açmamış, yüksek borç ve borç maliyeti özellikle az gelişmiş ülkeler için kronik bir problem olarak bilinmekte idi. Ancak her ne kadar krizin ayak sesleri gelse de 2008 yılında patlak veren ve Amerikan konut piyasasında yaşanan düşüş ile subprime mortgage denilen kredi piyasasınn çöküşü, 2000'li yıllardan bu yana aşırı büyüyen türev piyasaları etkilemiş ve bağlantılı bankaları, yani finansal sistemi iflas noktasına getirmiştir. Mali piyasaların uluslar üstü bir ağa sahip olması krizin bütün dünyaya yayılmasına sebep olmuştur. İşte bu noktada borç krizi, kimi ülkelerde uluslararası para sistemi, ekonomik tercihler, cari açı, bölgesel kalkınma ve yatırımlar amacıyla yapılan borçlanmanın etkin kullanılamaması gibi sebeplerle ortaya çıkmış ve günümüzde çok ciddi bir sorun haline gelmiştir. Tebliğimizde bu soruna yönelik ekonometrik bir değerlendirme sonrası tespitlerimize ve Avrupa'da borç krizine karşı çözüm önlemlerimize yer vereceğiz.

Anahtar Kelimeler: borç, finansal kriz, Euro bölgesi krizi, finans

\section{Abstract}

Since the World Economic Depression of 1929 in developed economies, the economic crisis did not cause a serious debt problem, especially in less-developed countries, high debt and cost of debt was known as a chronic problem. However, although the sound of footsteps, the crisis erupted in 2008, and with the decline in the U.S. housing market, the so-called subprime mortgage collapse of credit markets, over-growing derivatives markets since the 2000s, and the associated impact on banks, ie, the financial system has brought to the point of bankruptcy. Have a

\footnotetext{
* Doç. Dr. Gazi Üniversitesi İ.I.B.F. Maliye Bölümü

** Arş. Gör. Hacettepe Üniversitesi İ.̇.B.F. Maliye Bölümü
} 
transnational network of financial markets, crisis has led to the spread of the whole world. At this point the sovereign debt crisis in some countries, the international monetary system, economic preferences, the current account deficit, borrowing for the purpose of regional development and investments have emerged for reasons such as ineffective use of resources, and today has become a very serious problem. In our paper, to address this issue we will provide a solution to the debt crisis in Europe and measures after an assessment will have determined in econometric.

Keywords: debt, financial crisis, Euro zone crisis, finance

JEL Classification Codes: H63, G01, F65

\section{Giriş}

2007 yılının Temmuz ayının sonlarında A.B.D. konut kredisi piyasalarında iyice belirginleşen sorunların finansal piyasalarda yol açtığı sorunlar, tüm dünyada gözlerin bu ülkeye çevrilmesine yol açmıştır. Krizin ilk aşamasında olay, bir likidite krizi olarak görüldüğünden, A.B.D. ile paralel hareket eden Avrupa Merkez Bankası (AMB), Avro Alanında finansal piyasalara hızla emisyon ihracına başlamıştır. Dünyada 1900'lü yılların başından itibaren yaşanan ve en büyük Dünya Ekonomik krizi olarak ifade edilen 1929-1933 krizini, son yaşanan 2008 krizi hem derinlik hem de miktar olarak geçmiştir. ABD kaynaklı başlayan son kriz, tüm finansal ve reel sektörü etkilemiştir. Çünkü ABD 1980'li yıllardan bu yana sermaye hareketlerinin giderek serbestleştiği uluslararası piyasalardan en çok yabancı sermaye çeken ve dünyanın en büyük ekonomik büyüklüğüne sahip olması nedeniyle bu ülkede yaşanan kriz, bir dünya ekonomik krizine dönüşmüştür.

2008 krizi önceki yıllarda yaşanan krizlerden farklı olarak gelişmekte olan ekonomilerden çok, aralarında Avrupa Birliği (AB)'nin pek çok üyesinin de bulunduğu gelişmiş ekonomileri etkileyen bir küresel finansal kriz olarak dikkati çekmektedir.

Gelişmiş ülkeler ve özellikle $A B$ ülkeleri bu krizden en çok ve en uzun etkilenen ülkeler olmuştur. Finansal kriz olarak başlayan 2008 Dünya Ekonomik Krizi, AB ülkelerinde bir borç krizi haline dönüşmüştür. İlk borç krizinin patladığı ülke, Yunanistan olmuştur. Yunanistan'ın ardından İrlanda, Portekiz ve İspanya, krizin derinleştiği AB üyesi ülkeleri olurken, 
bu ülkeleri İtalya izlemiş ve uluslararası piyasalarda başta Belçika ve İngiltere olmak üzere diğer $A B$ ülkelerinin de krize gireceğine dair beklentileri başlatmıştır (AKÇAY, 2012).

Diğer taraftan borç krizinin kaçınılmaz sonucu olarak Uluslararası Kredi Derecelendirme kuruluşları da Gelişmiş Ülke notlarını ardı ardına indirmeye başlamıştır. Bu durum Borç krizini daha da derinleştirmiştir. Ayrıca giderek derinleşen borç krizi Avro alanında da çok büyük sorunları beraberinde getirdiği görülmektedir.

Çalışmamızda bu gelişmeler doğrultusunda ortaya çıan gelişmiş ülkeler borç krizi incelenerek, belirli parametreler üzerinden yaptığımız ekonometrik çalışmayla borç krizinin nedenleri ve çözüm önerilerine yer verilmiştir.

\section{Gelişmiş Ülkelerde Devlet Borçlarının Gelişimi}

Gelişmiş bir ekonomide borçlanma ile finansman daha çok ekonomik istikrarı sağlamak amacına yönelik olarak yapılmaktadır. Borçlanmanın gelişmiş bir ekonomideki en çok uygulanan şekli, bankacılık sektörüne veya halka satılabilir faizli borç senedi ihraç edilmesi şeklinde olmaktadır. Borç senetlerini elinde tutanlara göre finansmanının sonuçları da farklı olacaktır. Alacaklıların bankalar dışında olması halinde borçlanmanın ekonomideki genişletici etkisi daha az olacaktır. Borç senetlerinin bankalar dışına satılması durumunda, alacaklıların tahvil karşılığı verecekleri paraların, devlet tarafından harcanması nedeniyle, para arzında herhangi bir değişiklik meydana gelmeyecektir.

Tablo 1:

Gelişmiş Ekonomilerde Faiz Oranlan

\begin{tabular}{||l|l|l|l|l|l|l|l||}
\hline \hline & $\mathbf{2 0 0 5}$ & $\mathbf{2 0 0 6}$ & $\mathbf{2 0 0 7}$ & $\mathbf{2 0 0 8}$ & $\mathbf{2 0 0 9}$ & $\mathbf{2 0 1 0}$ & $\mathbf{2 0 1 1}$ \\
\hline ABD & 3.5 & 5.1 & 5.2 & 2.3 & 0.5 & 0.3 & 0.3 \\
\hline Japonya & 0.2 & 0.6 & 0.8 & 0.6 & 0.4 & 0.5 & 0.4 \\
\hline Kanada & 0.7 & 1.8 & 2.0 & 1.5 & 0.1 & 0.2 & 0.4 \\
\hline
\end{tabular}




\begin{tabular}{||l|l|l|l|l|l|l|l||}
\hline Euro Bölgesi & 2.1 & 3.1 & 4.3 & 4.6 & 1.2 & 0.8 & 1.4 \\
\hline İngiltere & 4.8 & 4.8 & 6.0 & 5.5 & 1.2 & 0.7 & 0.9 \\
\hline Fransa & 2.1 & 3.8 & 4.3 & 4.6 & 1.2 & 0.8 & 1.4 \\
\hline İsviçre & 0.5 & 1.4 & 2.1 & 0.1 & 0.1 & 0.1 & 0.0 \\
\hline
\end{tabular}

Kaynak: Kalkınma Bakanlığı; Ekonomik ve Sosyal Göstergeler (1950-2012), www.kalkınma.gov.tr Erişim tarihi: 14.03.2013.

Gelişmiş ekonomilerde iç borçlanmaya gidilmesi ekonomideki denge durumlarının göz önünde bulundurulması ile mümkün olmaktadır. $\mathrm{Bu}$ nedenle eğer ekonomi eksik istihdamda ise borçlanma yoluyla elde edilen fonlar, üretim faktörlerinin tam istihdamını sağlayacak şekilde kullanılacaktır. Buradaki esas sorun vergi ile borçlanmadan hangisine başvurulması gerektiğidir. Gelişmiş ekonomilerde eksik istihdam halinde, büyük ölçüde atıl bir üretim kapasitesi ve yaygın işsizlik söz konusudur. Böyle bir ekonomide toplam talep seviyesinde meydana gelecek bir artış fiyatlar genel seviyesinde artışa yol açarak reel geliri ve istihdam düzeyini yükseltecektir. Bu nedenle toplam talebi arttırmak için özel kesimin harcama seviyesini azaltacak mali bir tedbirden kaçınmak gerekecektir. Böyle bir durumda vergilemeye başvurmak olumsuz sonuçlara yol açacaktır. Bunun için borçlanmanın esas itibariyle vergilemeye tercih edilmesi gerekmektedir. Kişilerin tüketim veya yatırım için harcayacakları fonlardan beslenen borçlanma, toplam talep seviyesinde bir yükselişe yol açmayacaktır. Bu durumda borçlanma, tasarrufa ayrılan fonlardan beslenerek veya emisyona sebep olarak, her iki şekilde de para arzını arttıracak ve sonuçta toplam talep seviyesinin yükselmesine neden olacaktır (SAKAL, 1989).

Gelişmiş ülkelerde iç borçların ağırlığını uzun vadeli iç borçlar taşımaktadır. Ancak bu ülkelerin borçlarının vadesi 13-15 yıl arasında değişmekte ve faiz oranları 2008 krizine kadar \% 2-4 arasında değişirken, kriz ile birlikte 2009 yılından itibaren faiz oranları \%0'a yaklaşmıştır.

\section{A. Gelişmiş Ülkelerde Borç Krizi}


2008 yılı Eylül ayında, ABD’nin dördüncü büyük yatırım bankası olan Lehman Brothers'in iflas etmesiyle patlak veren kriz kısa sürede tüm dünyaya yayılarak küresel çapta bir mali ve reel sektör krizine dönüşmüştür. Krizin olumsuz etkileri $\mathrm{AB}^{\prime}$ nde de ciddi boyutlarda hissedilmiş ve Euro Alanı 2009 yılında \% 4,1 oranında küçülerek tarihindeki en büyük daralmayı yaşamıştır (T.C. Başbakanlık Avrupa Birliği Genel Sekreterliği, 2011). Yaşanan küresel kriz, AB ülkelerinde kamu açıkları ve borç stoklarının ciddi boyutlarda artmasına ve birçok üye ülkede kamu maliyesinin sürdürülebilirliğinin tehlikeye girmesine neden olmuştur. Nitekim 2006 yllında 7,1 trilyon Euro olan AB hükümetlerinin borç yükü 2009 yılı sonunda kurtarma paketlerinin de devreye girmesi ile 8,6 trilyon Euro'ya yükselmiştir (USAK, 2011).

Borçlanma oranları kriz öncesinde son derece düşük olan gelişmiş ülkelerin ekonomileri kriz ve krizden çıkış programları nedeniyle yavaşlamaya döndüğünden, borçların çevrilebilirliğiyle ilgili beklentiler bozulmuş, borçlanma maliyetleri yükselmiştir (European Central Bank, 2013).

Küresel krizin ortadan kaldırılması için 2008 yılından itibaren izlenen genişletici politikalar yeni kriz dinamikleri doğurmuştur. Maliye politikası ekonomide çarkların yeniden dönmesini sağlamak üzere gevşetilmiştir. Vergiler azaltılmış, harcamalar artırılmış, oluşan bütçe açığı borçlanmayla kapatılmıştır. Tablo 2'de görüldüğü gibi uygulanan programların büyüklüğü nedeniyle ciddi bir borçlanma söz konusu olmuştur.

Tablo 3:

Gelişmiş Ülkelerde Genel Devlet Brüt Borç Stokunun GSYH Oranı

\begin{tabular}{||l|c|c|c|c|c|c|c|c|c||}
\hline & $\mathbf{2 0 0 0}$ & $\mathbf{2 0 0 5}$ & $\mathbf{2 0 0 6}$ & $\mathbf{2 0 0 7}$ & $\mathbf{2 0 0 8}$ & $\mathbf{2 0 0 9}$ & $\mathbf{2 0 1 0}$ & $\mathbf{2 0 1 1}$ & $\mathbf{2 0 1 2}$ \\
\hline ABD & 58.8 & 67.9 & 66.6 & 67.2 & 76.1 & 89.7 & 96.6 & 102.9 & 107.2 \\
\hline Japonya & 134.1 & 186.4 & 186.0 & 183.0 & 191.8 & 210.2 & 215.3 & 229.6 & 236.6 \\
\hline Kanada & 82.0 & 71.6 & 70.3 & 66.5 & 71.3 & 83.3 & 85.1 & 85.4 & 87.5 \\
\hline
\end{tabular}


Uşak Üniversitesi Sosyal Bilimler Dergisi

$2013,6 / 3$

M. MERIC , E. ATSAN

\begin{tabular}{|l|c|c|c|c|c|c|c|c|c||}
\hline Avustralya & 25.2 & 10.9 & 10.0 & 9.7 & 11.8 & 16.9 & 20.5 & 24.2 & 27.1 \\
\hline Kore & 17.4 & 26.7 & 31.1 & 30.7 & 30.1 & 33.8 & 33.4 & 34.2 & 33.5 \\
\hline Almanya & 60.9 & 68.5 & 67.9 & 65.4 & 66.9 & 74.7 & 82.4 & 80.6 & 83.0 \\
\hline Fransa & 65.2 & 66.7 & 64.1 & 64.2 & 68.2 & 79.2 & 82.3 & 86.0 & 90.0 \\
\hline İtalya & 108.2 & 105.4 & 106.1 & 103.1 & 105.7 & 116.0 & 118.6 & 120.1 & 126.3 \\
\hline İngiltere & 37.8 & 41.8 & 43.0 & 43.7 & 52.2 & 68.0 & 75.0 & 81.8 & 88.7 \\
\hline Avusturya & 67.0 & 64.2 & 62.3 & 60.2 & 63.8 & 69.2 & 71.8 & 72.3 & 74.3 \\
\hline Belçika & 106.5 & 92.0 & 88.0 & 84.0 & 89.3 & 95.7 & 95.6 & 97.8 & 99.0 \\
\hline Danimarka & 54.3 & 45.4 & 41.0 & 34.1 & 41.9 & 40.6 & 42.9 & 44.1 & 47.1 \\
\hline Finlandiya & 42.5 & 41.7 & 39.6 & 35.2 & 33.9 & 43.5 & 48.6 & 49.1 & 52.6 \\
\hline Yunanistan & 106.2 & 101.2 & 107.3 & 107.4 & 112.6 & 129.0 & 144.6 & 165.4 & 170.7 \\
\hline İzlanda & 42.0 & 25.4 & 30.1 & 29.1 & 70.3 & 88.2 & 92.8 & 99.2 & 94.2 \\
\hline İlanda & 38.4 & 27.1 & 24.8 & 25.0 & 44.5 & 64.9 & 92.2 & 106.5 & 117.7 \\
\hline Hollanda & 50.7 & 51.8 & 47.4 & 45.3 & 58.5 & 60.8 & 62.9 & 65.2 & 66.2 \\
\hline Norveç & 30.0 & 47.8 & 59.0 & 56.8 & 54.3 & 48.9 & 49.6 & 49.6 & 49.6 \\
\hline Portekiz & 53.3 & 62.5 & 63.7 & 68.3 & 71.6 & 83.1 & 93.3 & 107.8 & 119.1 \\
\hline Ispanya & 55.6 & 43.2 & 39.7 & 36.3 & 40.2 & 53.9 & 61.3 & 69.1 & 90.7 \\
\hline
\end{tabular}


Uşak Üniversitesi Sosyal Bilimler Dergisi

$2013,6 / 3$

M. MERIÇ, E. ATSAN

\begin{tabular}{|l|l|l|l|l|l|l|l|l|l||}
\hline İsveç & 54.1 & 50.0 & 44.8 & 39.7 & 38.4 & 42.0 & 38.8 & 37.9 & 37.1 \\
\hline Euro Bölgesi & 68.2 & 70.2 & 68.6 & 66.4 & 70.2 & 80.0 & 85.4 & 88.0 & 93.6 \\
\hline G-7 & 77.5 & 88.1 & 85.5 & 83.5 & 91.8 & 107.0 & 114.7 & 119.9 & 125.1 \\
\hline
\end{tabular}

Kaynak: IMF; World Economic Outlook Database, October, 2012.

Özellikle Euro Bölgesi ülkelerine ilişki endişeler artmış ve aynı dönemde $A B D$ ise borç tavanının artırılması için siyasi çekişmelere sahne olmuş ve bu esnada tarihte ilk defa kredi notu kırılmıştır. Çözüm için hayati öneme sahip büyüme gerçekleştirilememiştir. Diğer taraftan Tablo 3'de görüldüğü gibi bazı Avrupa ülkelerinde bütçe açığı çok yüksek oranlara çıkmış ve 2010 yılından itibaren çok büyük oranlarda olmayan azalma görülse de, bütçe açıklarının varlığını koruması nedeniyle borç stokunun artışını sürdürdüğü görülmektedir.

Tablo 3:

Gelişmiş (G-7) Ülkelerde Bütçe Açıklarının GSYH Oranı

\begin{tabular}{||c|c|c|c|c|c|c|c|c||}
\hline & $\mathbf{2 0 0 6}$ & $\mathbf{2 0 0 7}$ & $\mathbf{2 0 0 8}$ & $\mathbf{2 0 0 9}$ & $\mathbf{2 0 1 0}$ & $\mathbf{2 0 1 1}$ & $\mathbf{2 0 1 2}$ & $\mathbf{2 0 1 3}$ \\
\hline ABD & 2.7 & 3.3 & 5.5 & 8.4 & 8.7 & 7.9 & 6.8 & 6.5 \\
\hline Japonya & 3.5 & 2.2 & 3.5 & 7.4 & 7.9 & 8.3 & 9.1 & 5.6 \\
\hline Kanada & 0.8 & 0.5 & 0.6 & 2.5 & 4.1 & 3.4 & 2.9 & 2.1 \\
\hline Almanya & 2.3 & 1.1 & 0.9 & 1.2 & 2.3 & 0.9 & 0.5 & 0.3 \\
\hline Fransa & 2.2 & 3.0 & 3.0 & 4.7 & 4.6 & 3.5 & 2.8 & 1.4 \\
\hline İtalya & 4.1 & 3.3 & 3.5 & 3.6 & 3.3 & 3.4 & 0.6 & 0.0 \\
\hline \hline
\end{tabular}




\begin{tabular}{||c|c|c|c|c|c|c|c|c||}
\hline \hline İngiltere & 4.7 & 5.2 & 7.2 & 9.7 & 8.5 & 6.6 & 5.4 & 4.0 \\
\hline Euro Bölgesi & 2.4 & 2.3 & 2.9 & 4.4 & 4.2 & 3.4 & 2.1 & .0 \\
\hline G-7 & 2.9 & 2.9 & 4.2 & 6.6 & 7.0 & 6.3 & 5.6 & 4.6 \\
\hline
\end{tabular}

Kaynak: IMF; World Economic Outlook Database, October, 2012

Euro Bölgesi'ne dâhil olan üye devletlerde ortak para birimi olan Euro'nun kullanılması ve bu ülkelerde para politikasının Avrupa Merkez Bankası (AMB) aracılığı ile tek bir elden yürütülüyor olması, söz konusu ülke ekonomilerinin birbirine sıkı bir şekilde bağlı olmasına ve bir Euro Bölgesi ülkesinde meydana gelen olumsuz gelişmelerin diğer Euro Bölgesi ülkelerine de kısa sürede yayılmasına yol açmaktadır. Bu hususun yanı sıra, $\mathrm{AB}$ üyesi ülkelerin finans ve reel sektörlerinin yüksek entegrasyon düzeyi de ülkelerin birbirinden etkilenme seviyesini ve hızını artırmaktadır. Nitekim 2010 yılının ikinci çeyreğinde Yunanistan'da patlak veren borç krizi, kısa sürede diğer Euro Bölgesi ülkelerini ve hatta ekonomik ve parasal birliğin geleceğini tehdit altına sokmuştur.

Başta Almanya olmak üzere bazı üye ülkelerin Yunanistan'a yardım konusunda isteksiz olması, piyasalarda panik havasının yayılmasına neden olmuş ve sonuçta kamu maliyesi ve bankacılık kesimleri sorunlu olan İrlanda, Portekiz, İspanya, İtalya ve Belçika da borç krizine sürüklenme tehdidi ile karşı karşıya kalmışlardır.

\section{B. Gelişmiş Ülkelerde Borç Krizinin Nedenlerinin Tespitine Yönelik Ekonometrik Analiz}

\section{Değişkenler ve Veriler}

Gelişmiş olan ülkelerde borç sorunu ile ilgili literatürde borç miktarına yol açan birçok faktör ele alınmaktadır. Özellikle gelişmekte olan ülkelerde tasarruf oranı belirleyici iken gelişmiş ülkelerde üzerinde neredeyse görüş birliğine varılan faktörler ödemeler dengesi açığı, kamu harcamaları, büyüme oranı ve reel faiz oranlarıdır. 
Ödemeler dengesi fazlası durumunda ülke, ticareti finanse etmek için borçlanmaya ihtiyaç duymayacaktır. Açık olması durumunda ise borçlanma ihtiyacı artacaktır. Aşırı kamu harcamaları da borç düzeyini ciddi oranda yükseltebilir. Her ne kadar akademik çalışmalarda borçlanmanın büyüme üzerindeki etkileri yoğun şekilde araştırılsa da büyüme ile borç yükü arasında da bir ilişki bulunmaktadır. Şöyle ki GDP'deki reel bir büyüme ile birlikte devletin özellikle ödemeler dengesi açığını finanse etmesi ve hasıladaki bir artış ile fazla borç yükünü kompanse etmesi beklenmektedir. Nitekim borçlanmanın büyüme üzerindeki etkilerinin tespiti ile hükümetler artık borçlanma konusunda artık daha cesur adımlar atabilmektedirler. Bu tutum artık borç yükünün büyüme üzerindeki etkisinin yerini büyümenin borç yükü üzerindeki etkisi şeklini almıştır. Borçlarla ödemeler dengesi açığı, kamu harcamaları arasında pozitif bir ilişki beklenirken, büyüme oranı ve reel faiz oranları ile negatif bir ilişkisinin olması beklenmektedir.

Değişkenlere ait 1991-2010 yıllarını kapsayan veriler OECD, IMF ve Birleşmiş Milletlerin veri bankalarından elde edilmiştir. Kamu borç yükünün gelişmiş ülkelerde özellikle 1991 sonrası dönemde artış göstermesi modelimizde zaman aralığı olarak 1991 - 2010 dönemini almamızda etkili olmuştur.

\section{Model}

Bu çalışmada gelişmiş ülkelerde G-7 ülkeleri (Amerika Birleşik Devletleri, Japonya, Almanya, Fransa, İngiltere, İtalya ve Kanada) kamu borç stoğunun GSYİH'ya oranı üzerinde kamu harcamaları oranı, cari işlemler dengesi, büyüme oranı ve reel faiz oranlarının etkisi 1991 - 2010 dönemleri itibariyle panel veri yöntemiyle analiz edilecektir.

$$
\begin{aligned}
& L N_{-} K B S O_{i t}=\alpha 0+\beta_{1} K H O_{i t}+\beta_{2} C D O_{i t}+\beta_{3} B O_{i t}+\beta_{4} R F O_{i t}+v_{i t} \\
& i=1, \ldots, 7, t=1, \ldots, 20
\end{aligned}
$$

$$
\beta_{1}>0, \beta_{2}>0, \beta_{3}<0, \beta_{4}<0
$$

Yukarıdaki regresyon denkleminde $\mathrm{i}$, birim sayısını, $\mathrm{t}$ ise zaman aralığını göstermektedir. Burada LN_KBSO bağımlı değişken olup kamu borç stok oranının doğal logaritmasını, KHOt-1 bir dönem önceki kamu harcamalarının GDP'ye oranını (Kamu harcamalarının bir dönem sonraki borç yükünü etkilediği varsayılmıştır), $\mathrm{BO}_{\mathrm{t}}$ büyüme oranını, $\mathrm{RFO}_{\mathrm{t}}$ reel faiz 
Uşak Üniversitesi Sosyal Bilimler Dergisi

$2013,6 / 3$

M. MERIÇ, E. ATSAN

oranını göstermektedir. $\alpha$ oise gözlenemeyen birim etkiyi ifade etmektedir. Modelde negatif değişkenlerin logaritmalarının alınması bu değişkenleri anlamsız hale getirmektedir. Bu nedenle modeldeki 2 değişkenin negatif değerlere sahip olması tam logaritmik bir model kurmamızı engellemiştir. Ancak yarı logaritmik bir model kurarak açılayıcı değişkenlerin eğim katsayıları yarı esneklikleri, yani açılayıcı değişkendeki bir birimlik değişmeye karşılık bağımlı değişkendeki yüzde değişmeye ulaşmış olacağız. Ekonometrik çalışmamızda E-Views 7 programından faydalanılmıştır.

Dependent Variable: LN_KBSO

Method: Panel Least Squares

Date: 04/30/13 Time: 20:56

Sample (adjusted): 19912010

Periods included: 20

Cross-sections included: 7

Total panel (balanced) observations: 140

\begin{tabular}{ccccc}
\hline \hline Variable & Coefficient & Std. Error & t-Statistic & Prob. \\
\hline \hline C & 4.298851 & 0.215097 & 19.98568 & 0.0000 \\
KHO(-1) & 0.005316 & 0.005138 & 1.034807 & 0.3026 \\
CDO & 0.047265 & 0.011251 & 4.200804 & 0.0000 \\
BO & -0.034560 & 0.014640 & -2.360688 & 0.0197 \\
RFO & -0.027884 & 0.014251 & -1.956604 & 0.0525 \\
\hline \hline & & & & \\
R-squared & 0.884492 & Mean dependent var & 4.342352 \\
Adjusted R-squared & 0.860329 & S.D. dependent var & 0.388379 \\
S.E. of regression & 0.355885 & Akaike info criterion & 0.806644 \\
Sum squared resid & 17.09833 & Schwarz criterion & 0.911703 \\
Log likelihood & -51.46509 & Hannan-Quinn criter. & 0.849337 \\
F-statistic & 7.635263 & Durbin-Watson stat & 0.110468
\end{tabular}


Uşak Üniversitesi Sosyal Bilimler Dergisi

$2013,6 / 3$

M. MERIÇ, E. ATSAN

Prob(F-statistic)

0.000014

Grafik 1. Yıllar itibariyle G7 ülkelerinin Kamu Borç Stoğu, Kamu Harcamaları, Cari Denge, Büyüme Oranı ve Reel Faiz Oranları Seyri

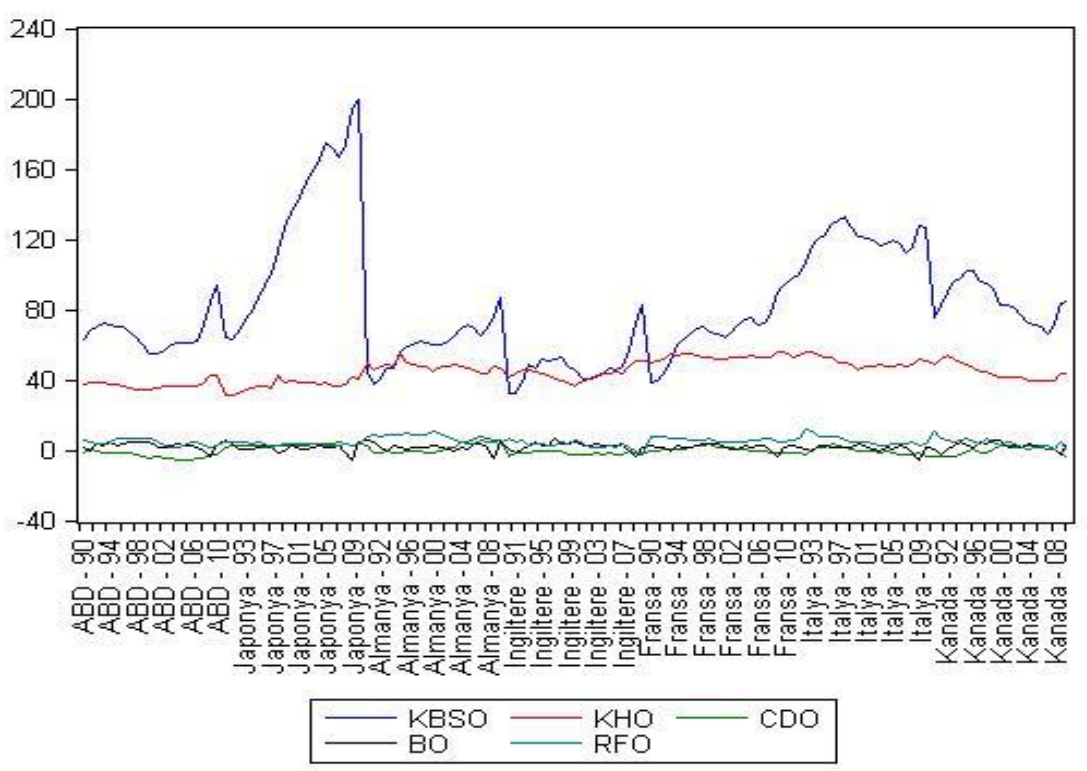

Kaynak: IMF, OECD, UN veri bankaları

Analiz sonuçları, Langrange Çarpan (LM) ve Hausman testleri yapılmıştır. $M$ test sonucuna göre, REM, ROLS'na göre; Hausman test sonucuna göre ise deREM, FEM'ne göre daha tercih edilebilir bulunmuştur. Buna göre 7 ülke 140 gözlem aralığı itibariyle yukarıda belirtilen sonuçlara ulaşılmıştır. En Küçük Kareler yöntemi ile yapılan analizde ödemeler dengesi açı̆̆ı, kamu harcamaları, büyüme oranı ve reel faiz oranının borç düzeyi üzerinde anlamlı bir etkiye sahiptir. Bu faktörlerden cari denge oranı ve büyüme oranı daha fazla etkili görünmektedir. Buna göre cari denge oranındaki bir birimlik artış borç yükünün reel GDP'ye oranını \% 4,49 birim artırırken, kamu harcamalarının reel GDP'deki oranında bir birimlik artış borç yükünün reel GDP'ye oranını \% 1,03 birim artırmaktadır. Ancak kamu harcamaları verilerinin olasılık değeri \% 30 civarında çıkması sebebiyle kullanılabilirliği pek anlamlı çıkmamıştır. Büyüme oranındaki bir birim artış 
ise borç yükünün reel GDP'ye oranını \% 2,36 birim azaltmaktadır. Reel faiz oranlarındaki bir birim artış ise borç yükünün reel GDP'ye oranını \% 1,95 birim azaltmaktadır.

\section{Birim Kök Analizi}

Uygulamada serilerin durağanlık özelliklerinin test edilmesinde en çok kullanılan yöntemler; Dickey ve Fuller (1979), Genişletilmiş Dickey ve Fuller (ADF) (1981), Phillips-Perron (PP) (1988) testleridir. Bu çalışmada serilerin durağan olup olmadıklarının belirlenmesinde ADF ve PP birim kök testlerinden yararlanılmıştır.

Tablo 4:

Birim Kök Test Sonuçları

\begin{tabular}{|l|l|l|l|l|}
\hline \multirow{2}{*}{ Değişken } & \multicolumn{2}{|c|}{ ADF } & \multicolumn{2}{c|}{ PP } \\
\cline { 2 - 5 } & Test İst.* $^{*}$ & Olasılık** & Test İst. & Olasılık \\
\hline LN_KBSO & -2.02173 & 0.0216 & 0.74113 & 0.7707 \\
\hline CDO & 0.54359 & 0.7066 & 0.24313 & 0.5960 \\
\hline BO & -5.04098 & 0.2105 & -5.72143 & 0.1522 \\
\hline RFO & -0.12437 & 0.4505 & -0.41140 & 0.3404 \\
\hline
\end{tabular}

NOT: $\left(^{*}\right)$ Gecikme uzunluğunu göstermektedir. Gecikme uzunluğu seçiminde ADF için Akaike bilgi kriteri kullanılmıştır. 0.05'in üzerindeki değerler birim kök varlığını ifade eden boş hipotezin red edilemeyeceğini gösterir. ${ }^{* *}$ PP testinde Newey-West bilgi kriteri kullanılmıştır

ADF ve PP testlerinde boş hipotez serilerin durağan olmadığını, yani birim kök içerdiklerini ifade etmektedir.

\section{Borç Krize Karşı Alınan Çözüm Önlemleri}

Avrupa kadar zor durumda görünmese de özellikle borçlanma tavanının artırılmasında yaşanan tartışmalar ve kaybedilen zaman ABD'nin krizden çıkışının ertelemesine neden olduğu görülmektedir. Ekonomi yönetimi büyümeyi desteklemek üzere vergisel avantajlar, harcama ve para basımını içeren iki milyar dolarlık bir tedbir paketi açıklamıştır. Özellikle 1 
Uşak Üniversitesi Sosyal Bilimler Dergisi

$2013,6 / 3$

M. MERIÇ, E. ATSAN

trilyon dolara yakın olarak basılan dolarla, ABD rezerv paraya sahip olma avantajını kullanmış ve bunun sonucunda borçlanma maliyetini düşürerek, borçlanmaya devam etmesi kolaylaşmış görülmektedir (BBC News, 2012).

Euro Alanı ülkelerinin ise ekonomik performanslarında son yıllarda gözlemlenen gerileme ekonomik krizle birlikte daha da belirgin bir hale gelmiş ve bu durum Euro'nun, dolayısıyla Ekonomik ve Parasal Birliğin ve nihayetinde $A B^{\prime}$ nin geleceğine dair endişeleri artırmıştır. Özellikle Almanya ve Fransa gibi $A B^{\prime}$ nin siyasi bir proje olduğunu savunan bazı $A B$ ülkeleri, mevcut $\mathrm{AB}$ politikalarının yaşanmakta olan sorunların çözümünde yetersiz kaldığını, özellikle Euro Alanı'nda makroekonomik gözetimin ötesinde bir ekonomik koordinasyona ihtiyaç duyulduğunu ve bu çerçevede $A B$ düzeyinde yeni mekanizmalar oluşturulması gerektiğini savunmaktadırlar. $\mathrm{Bu}$ yaklaşım çerçevesinde, yalnızca para politikasının değil, üye ülkelerce uygulanacak maliye politikalarının da $\mathrm{AB}$ ölçeğinde çok daha sıkı kurallara tabi tutulması ve Euro Alanı ülkeleri arasındaki ekonomik politikaların uyumlaştırılması gerektiği belirtilmektedir.

Her ne kadar henüz $A B$ düzeyinde gelecekte uygulanacak mekanizmaların kapsam ve derinliğine ilişkin tam bir mutabakat oluşmamış gibi görünse de, küresel kriz ve bunun sonrasında $A B$ üyesi ülke ekonomilerinin bu krize verdiği tepki, $\mathrm{AB}^{\prime}$ de ekonomik yönetişim alanında kapsamlı reformlar yapılması gerektiği kabul edilebilir bir görüş olarak yaygınlaşmaktadır. Bu kapsamda, ilk olarak 29 Eylül 2010 tarihinde, İstikrar ve Büyüme Paktı'nın kabulünden bu yana $A B^{\prime}$ nin ekonomik yönetişiminde en önemli aşamayı temsil eden ve başta Euro Alanı olmak üzere, $A B^{\prime}$ de bütçe ve makroekonomik gözetim ve denetimi güçlendirmeyi amaçlayan kapsamlı bir ekonomik yönetişim paketi kabul edilmiştir (T.C. Başbakanlık Avrupa Birliği Genel Sekreterliği, 2011). Ayrıca, makroekonomik istikrarsızlıkları gidermeye yönelik olarak alınan önlemler çerçevesinde, Avrupa İstikrar Mekanizması'nın oluşturulması planlanmış ve söz konusu mekanizmanın 2013 yılının ortasında faaliyete geçmesi kararlaştırılmıştır (T.C. Başbakanlık Avrupa Birliği Genel Sekreterliği, 2011).

$\mathrm{Bu}$ gelişmeleri takiben kamu borcunun çevrilebilirliğine ilişkin sorunlar nedeniyle Yunanistan'ın yaşamakta olduğu krizin diğer AB üyesi ülkelere de sıçramasının engellenmesi ve Euro'nun korunması amacıyla, Euro Alanı ülkeleri 2010 yılı Mart ayında Yunanistan'a yardım sağlanmasına yönelik IMF ile ortak bir finansal yardım mekanizması oluşturulması için anlaşmışlardır. Bu gelişmeyi takiben, 11 Nisan 2010 tarihinde Yunanistan'a 
ilk dilim olarak 30 milyar Euro tutarında acil yardım sağlanması hususu da Euro Alanı Maliye Bakanları tarafından onaylanmıştır. Bu gelişmelerin sonucunda $A B$ ve IMF'nin katkısıyla oluşturulan toplam 110 milyar Euro tutarındaki 3 yıl vadeli kurtarma paketi Yunanistan'a tahsis edilmiştir.

Ardından, 28 Kasım 2010'da İrlanda, bankacılık sektöründe yaşadığ 1 sorunlar nedeniyle $\mathrm{AB}^{\prime}$ ye yardım talebi ile başvurmuş ve İrlanda için ABIMF işbirliğinde 85 milyar Euro tutarında bir kurtarma paketi açıklanmıştır. Son olarak Portekiz 6 Nisan 2011 tarihinde AB'den yardım istemiş olup, Portekiz'e AB-IMF işbirliğinde 78 milyar Euro tutarında yardım yapılması kararlaştırılmıştır (T.C. Başbakanlık Avrupa Birliği Genel Sekreterliği, 2011).

Krize karşı bir önlem olarak kurulan $\mathrm{AB}$ mekanizmalarının ardındaki çıkış noktası, uyguladıkları sürdürülemez maliye politikaları sonucunda ciddi borç yükü altına giren Euro Bölgesi ülkelerinin borçlanma maliyetlerinin de önemli ölçüde artması sonucunda daha derin mali problemlerle karşı karşıya kalmış olmalarıdır. Kurulan mekanizmaların temel amacı mali sorunlarla karşı karşıya kalan ülkelerin borçlanma maliyetlerini düşürebilmektir. Borçlanma maliyetlerini kısa vadede düşürebilmenin en etkili yollarından biri ise Euro Bölgesi'nin bir bütün olarak borçlanması ve mali problemlerle karşı karşıya kalan üye devletlere daha uygun koşullarla kredi temin edilmesidir. Bu yöntemle, Yunanistan, İspanya, İrlanda, Portekiz gibi düşük kredi notuna sahip ülkeler iyi kredi notlarına sahip Almanya, Fransa, Avusturya, Hollanda gibi ülkelerle aynı potada değerlendirilecek ve dolayısıyla $\mathrm{AB}$ şemsiyesi altında sağlanan daha uygun koşullu kredilerden faydalanabilecektir (AFONSO, FURCERI, GOMES, 2011).

\section{1. Ödemeler Dengesi Fonu (Balance of Payments Facility)}

Ödemeler Dengesi Fonu, Euro Bölgesi dışında kalan 10 AB üyesi devletin ödemeler dengesinde yaşayabilecekleri potansiyel sorunlarda ve buna bağlı olarak gerçekleşebilecek dış finansman güçlüklerinde devreye girmek üzere tesis edilmiştir. Böylelikle, $\mathrm{AB}^{\prime}$ nin mali istikrar ve dengesinin muhafaza edilmesi amaçlanmaktadır. Fonun finansmanı, AB Komisyonunun, $\mathrm{AB}$ bütçesi ve 27 üye devlet tarafından garanti altına alınan tahviller ihraç ederek borçlanması ve ödemeler dengesinde sorun yaşayan devletlere kredi sağlaması şeklinde gerçekleşecektir.

Fondan faydalanan devletlerin ödemeler dengelerini sağlıklı ve sürdürülebilir hale getirebilmeleri amacıyla gerekli ekonomi politikası 
Uşak Üniversitesi Sosyal Bilimler Dergisi

$2013,6 / 3$

M. MERIÇ, E. ATSAN

önlemlerini almaları gerekmektedir. Fonun kullanımı Komisyon ve üye devlet arasında Konseyin belirlediği koşulları temel alan bir sözleşme imzalanarak, Avrupa Parlamentosu ve AB Bakanlar Konseyinin onayı gerçekleşmektedir.

Toplam bütçesi 50 milyar Euro olan Ödemeler Dengesi Fonundan şu ana kadar Macaristan(6,5 milyar Euro), Letonya (3,1 milyar Euro) ve Romanya (5 milyar Euro) faydalanmıştır.

\section{Kredi Havuzu (Pooled Loans - Greek Loan Facility)}

Bir kereye mahsus olmak üzere oluşturulan bu mekanizma esas itibarıyla Yunanistan'a kredi sağlamak için tasarlanmış olup, Euro Bölgesi ülkelerinin Avrupa Komisyonu aracılığıyla sağladığı 80 milyar Euro ve IMF'nin temin ettiği 30 milyar Euro' dan oluşan 110 milyar Euro tutarında bir borç havuzudur (Council Regulation (EU), 2010).

\section{Avrupa Finansal İstikrar Mekanizması (European Financial Stability Mechanism-EFSM)}

$\mathrm{Bu}$ mekanizma, mali sorunlarla karşılaşan tüm $\mathrm{AB}$ üye devletlerine finansal destek sağlama amacıyla kurulmuş bir yapıdır. Bu mekanizma 11 Mayıs 2010 tarihinde kurulmuştur. Üye ülkenin doğal afetler veya kendi kontrolü dışında meydana gelen dış faktörler sebebiyle mali zorluklar yaşaması durumunda, Birliğin bu ülkeye mali yardım sağlayabilmesini düzenlemektedir.

EFSM, Euro Bölgesi dışında kalan üye devletlerin yararlandığı Ödemeler Dengesi Fonu ile benzer bir işleyiş sistemine sahiptir. Mekanizma uyarınca Komisyon, $\mathrm{AB}$ adına piyasalardan kredi temin etmekte ve sonrasında bu krediyi yararlanıcı üye ülkenin kullanımına sunmaktadır. Krediler $\mathrm{AB}$ bütçesi tarafından garanti altına alınmıştır. Krediden faydalanan ülkelerin Komisyon tarafından da kabul edilmiş sıkı bir makroekonomik uyum programı benimsemesi gerekmektedir. Mekanizmanın toplam büyüklüğü 60 milyar Euro'dur. EFSM çerçevesinde gerçekleştirilecek tüm işlemler Euro para birimi üzerinden yapılmak zorundadır. Avrupa Finansal İstikrar Mekanizması geçici bir mekanizma olup, 2013 yll Haziran ayından itibaren yerini Avrupa İstikrar Mekanizması'na (European Stability Mechanism-ESM) bırakacaktır (Council Regulation (EU), 2010). 
Uşak Üniversitesi Sosyal Bilimler Dergisi

$2013,6 / 3$

M. MERIÇ, E. ATSAN

EFSM, yaşadıkları krizlerin ardından mali yardım talebinde bulunan İlanda ve Portekiz için hazırlanan kurtarma paketlerine katkı sağlayacaktır. EFSM aracılığ 1 ile İrlanda'ya sağlanacak toplam kaynak 22,5 milyar Euro, Portekiz'e sağlanacak kaynak ise 26 milyar Euro'dur. Bu iki Devlet ayrıca EFSF ve IMF aracılığı ile de mali yardım alacaktır (İrlanda toplam 85 milyar Euro yardım alacakken, Portekiz için bu rakam 78 milyar Euro'dur) (http://ec.europa.eu, 2013).

\section{Avrupa Finansal İstikrar Fonu (European Financial Stability Facility - EFSF)}

Avrupa Finansal İstikrar Fonu 9 Mayıs 2010 tarihli AB Ekonomi ve Maliye Bakanları Konseyi (ECOFIN) kararı uyarınca, Euro Bölgesi'ne dâhil 16 üye devletin katılımıla 7 Haziran 2010'da Lüksemburg yasalarına tabi olan bir limited şirket olarak kurulmuştur. Fonun amacı çeşitli borç sorunları yaşayan Euro Bölgesi devletlerine geçici mali destek sağlayarak parasal birliğin mali istikrarını temin etmektir (tüm AB üyesi ülkelere mali destek sağlayabilen EFSM'den bu açıdan farklılaşmaktadır).

EFSF çerçevesinde, Euro Alanı'na dâhil olan üye devletler tarafından garanti altına alınmış ve toplam büyüklüğü 440 milyar Euro'yu aşmayacak şekilde piyasaya sürülmüş tahviller aracılığı ile mali açıdan zorluk yaşayan Euro Alanı ülkelerine kredi temin edilmesi öngörülmektedir. Mart 2011'e kadar fondan sadece İrlanda faydalanmıştır. Üç yıllık süreçte fondan çeşitli dilimler halinde toplam 17,7 milyar Euro8 alması öngörülen İlanda, ilk dilim olarak vadesi 2016 yılında dolacak 3,6 milyar Euro'luk bir kaynak almıştır.9 17 Mayıs 2011 tarihinde yardım paketi için AB ile anlaşmaya varan Portekiz de EFSF'den 26 milyar Euro kaynak sağlayacaktır.

EFSF geçici bir araç olup, Avrupa Finansal İstikrar Mekanizması gibi yerini 2013 yılının ortasından itibaren sürekli bir mekanizma olan Avrupa İstikrar Mekanizmasına (European Stability Mechanism) bırakacaktır.

\section{Avrupa İstikrar Mekanizması (European Stability Mechanism-ESM)}

28 Kasım 2010 tarihinde toplanan Euro Bölgesi'ne Üye Devletlerin Ekonomi ve Maliye Bakanları Konseyi'nde Avrupa İstikrar Mekanizması'nın kurulmasına karar verilmiştir. 24- 25 Mart 2011 tarihlerinde gerçekleştirilen AB Zirvesinde, 2013 yılı ortasında devreye girmesi öngörülen Avrupa İstikrar Mekanizması, Euro'nun istikrarını sağlamayı hedeflemektedir. 
Avrupa İstikrar Mekanizması'nın 700 milyar Euro tutarında sermaye tabanı olması ve bu sermaye tabanı aracılığı ile 500 milyar Euro tutarında kredi verilmesine (bu miktar en az beş yılda bir gözden geçirilecektir) imkân tanınması hedeflenmiştir. Sermayenin 80 milyar Euro tutarındaki bölümü nakit, 620 milyar Euro'luk bölümü ise hükümetler tarafından taahhüt edilen çekilebilir sermaye ve kefaletlerden oluşacaktır (EU, 2013).

\section{Faiz Dişı Fazla}

IMF'in klasik kriz uygulaması olan faiz dışı fazla sağlanması da programın önemli noktalarından biridir. Vergi ve özelleştirme ile gelirlerin artırılması, harcamaların kısılması ve özellikle sosyal güvenlik yüklerinin azaltılması yoluyla sağlanacak mali disiplinin faiz dışı fazlayı karşılaması düşünülmektedir. Artan borçlanma maliyeti sağlanması gereken faiz dışı fazlayı giderek daha da büyütmektedir. Bu durum ise hükümetleri faiz dışı fazla için yapabilecekleri tasarrufları uygulamalarını daha da zorlaştırmaktadır (T.C. Başbakanlık Avrupa Birliği Genel Sekreterliği, 2011).

\section{Enflasyonla Borcun Azaltılması}

Krizin çözümünün enflasyon artışı ile mümkün olabileceği de ifade edilmektedir. Enflasyonun borç stokunu eriterek borçlanma rasyolarını sürdürülebilir düzeylere çekmesinin sağlanabileceği ifade edilmektedir. Ancak enflasyonun bozucu etkilerinin daha belirgin olacağı, bu nedenle tehlikeli düzeylere ulaşmasının önlenmesi gerektiği fikri daha fazla taraftar bulmaktadır.

\section{Borçların Silinmesi}

Mali sektörün durumu da Avrupa ekonomisi açısından ciddi bir risktir. Sorunlu ülkelerin borçlarının döndürülmesi zorlaşmaktadır. Borçların silinmesi ihtimali giderek artmaktadır. Avrupa ekonomilerinin ağırlıklı olarak birbirlerinden borçlandıkları düşünüldüğünde, kredi sağlayan bankaların yaşayacağı mali bünye sorunları önemli bir sorun olabilir. Ekonomi yönetimleri mali sistemi kurtarmak için devasa maliyetler yüklenmek zorunda kalabilirler.

\section{Sonuç}

2008 kriz öncesi çalışmalarda az gelişmiş ve gelişmekte olan ülkelerin ekonomik krizler sonucunda yaşadıkları borç krizleri 2008 kriziyle birlikte format değiştirerek gelişmiş ülkelere yönelmiştir. Gelişmiş ülkelerde 
Uşak Üniversitesi Sosyal Bilimler Dergisi

$2013,6 / 3$

M. MERIÇ, E. ATSAN

ortaya çıkan kriz sonrasındaki borç kırılganlığı, $A B$ projesini ve özellikle Euro birlikteliğini sorgular hale getirmiştir. Çalışmada 2008 krizi sonrasında ortaya çıan aşırı borçlanma ihtiyacının nedenleri üzerinde yaptığımız çalışmada ele aldığımız borç stoku, büyüme oranı, dış ticaret, kamu harcamaları ve faiz oranlarının verilerinden hareketle yaptığımız ekonometrik analizde, büyüme oranı ve cari denge 'nin daha etkili olduğu görülmektedir. Faiz oranındaki azalmanın etkisi büyüme ve cari denge kadar olmasa da borçlanma üzerinde etkili olduğu görülmektedir. Kamu harcamalarının da borç stoku üzerinde etkisi olduğu görülmektedir.

Krizin analizde belirttiğimiz nedenler üzerinde etkili olmasından dolayı ortaya çıkan borç krizini önlemek amaciyla uygulamaya konulan kurtarma paketlerinin uygulamaları günümüzde halen devam etmektedir. $\mathrm{Bu}$ paketler görünürde borç krizini durdurmuş gibi görünse de en son Güney Kıbrıs'ta ortaya çıkan bankacilık krizi, borç krizine dönüşmüş görünmektedir. Bu nedenle istikrar paketlerinin borç krizini önlemede etkili olduğunu söyleyebiliriz: Fakat bu paketlerin borç krizi ortaya çıkmadan önce ülkelerde kullanılabilmesinin daha etkili olacağını söyleyebiliriz. Diğer taraftan borçlanma nedenlerini özellikle büyümeyi artırmadan borç krizinin çözülmesi de zor görünmektedir. Ekonomik büyümeyi artırma konusunda da dikkatli davranılması gerekmektedir şöyle ki kamu borcu üzerinde cari açığın etkisi büyümeden daha fazla olmakta cari açık konusunda gerekli tedbirleri alarak borç sorununun çözümünde adımlar atılmalıdır. Bu aşamada tamamen cari açı̆̆ın finansmanından ziyade çoklu hedeflerin izlenebileceği dereceli olarak zamana yayılmış bir politika sepetinin daha etkin olacağı düşünülmektedir.

\section{Kaynakça:}

AFONSO A., FURCERI D., GOMES P.; “Credit Ratings and the Euro Area Sovereign Debt Crisis", Europian Central Bank, working paper series, No: 1347, June 2011.

AKÇAY, Belgin; Yunanistan Ekonomisinde Devlet Borç Krizi-Cari Açık İlişkisi, Maliye Dergisi Sayı 163, Temmuz-Aralık 2012.

BBC News; Tiİrlandameline: The unfolding eurozone crisis, 13 July 2012 www.bbc.co.uk/.../business-138565, Erişim tarihi, 15.03.2013.

Council Regulation (EU); Establishing a European Financial Stabilisation Mechanism. No 407/2010 of 11 May 2010. 
Uşak Üniversitesi Sosyal Bilimler Dergisi

$2013,6 / 3$

M. MERIÇ, E. ATSAN

http://ec.europa.eu/economy finance/eu borrower/greek loan facili ty/index en.htm. Erişim tarihi: 15.03.2013.

Council Regulation (EU); Establishing a European Financial

Stabilisation Mechanism. No. 407/2010 of 11 May 2010.

Erişim tarihi: 15.03.2013.

http://ec.europa.eu/economy finance/eu borrower/greek loan facility/i ndex en.htm. Erişim tarihi: 15.03.2013.

CHECHERIT, Cristina - ROTHER Philipp; “The Impact of High and Growing Government Debt on Economic Growth An Empirical Investigation For The Euro Area", European Central Bank, August 2010.

EU; Conclusions of the Heads of State or Government of the Euro Area of 24-25 March 2011.

European Central Bank. Monthly Bulletin. February 2013.

www.ecb.int/pub/pdf/mobu/mb201111en.pdf. Erişim tarihi: 14.03.2013.

IMF; World Economic Outlook Database, October, 2012.

www.oecd.org. Erişim tarihi: Mayıs, 2013.

unstats.un.org. Erişim tarihi: Mayıs, 2013.

Kalkınma Bakanlığı; Ekonomik ve Sosyal Göstergeler (1950-2012), www.kalkınma.gov.tr. Erişim tarihi: 14.03.2013.

SAKAL, Mustafa; Türkiye'de 1980 sonrası İç Kamu Borçlanması ve Sonuçları, Yüksek Lisans Tezi, İzmir 1989.

T.C. Başbakanlık Avrupa Birliği Genel Sekreterliği; Avrupa Birliği'nde Küresel Finansal Krize Karşı Alınan Önlemler ve Birliğin Rekabet Gücünün Arttırılmasına Yönelik Girişimler: “Euro Rekabet Paktı", Mayıs 2011, Ankara, s.1., Eurostat, epp.eurostat.ec.europa.eu.

Uluslararası Stratejik Araştırmalar Kurumu (USAK); “Krizdeki Birlik: Euro Bölgesi'nin Borç Sarmalı ve AB'nin Geleceği", USAK AB Araştırmaları Merkezi, USAK Raporları No 11-01, Mart 2011. 